Bài báo Khoa học

\title{
Nghiên cứu cải tiến hệ thống truyền tin và tự động hóa cho các thiết bị đo mưa, gió thủ công trên khu vực đồng bằng Bắc bộ
}

\author{
Nguyễn Hữu Tài ${ }^{*}$, Đào Văn Sản ${ }^{2}$, Nguyễn Hồng Hạnh ${ }^{3}$
}

${ }^{1}$ Trung tâm Quan trắc khí tượng thủy văn; taikttv@gmail.com

2 Đài khí tượng Thủy văn khu vực đồng bằng Bắc Bộ; sandaovankttv@gmail.com

${ }^{3}$ Đài khí tượng Thủy văn khu vực đồng bằng Bắc Bộ; hanh1983hn@yahoo.com

* Tác giả liên hệ: taikttv@gmail.com; Tel: +84-915595773

Ban Biên tập nhận bài: 16/11/2020; Ngày phản biện xong: 17/01/2021; Ngày đăng: $25 / 02 / 2021$

Tóm tắt: Thời gian qua, những hiện tượng thời tiết bất thường và khắc nghiệt ở Việt Nam diễn biến ngày càng phức tạp. Trước tình hình này, yêu cầu về số liệu quan trắc đòi hỏi phải chính xác, kịp thời. Theo Chiến lược phát triển ngành Khí tượng Thủy văn (KTTV) đến năm 2020, quan điểm nhà nước ta đối với ngành là: phát triển đồng bộ theo hướng hiện đại hoá; lấy việc đầu tư cho khoa học, công nghệ và đào tạo nguồn nhân lực làm giải pháp chủ yếu để phát triển trên cơ sở kế thừa và phát huy tối đa nguồn lực hiện có; khai thác triệt để thành tựu khoa học, công nghệ trong nước, đồng thời ứng dụng chọn lọc những thành tựu khoa học công nghệ tiên tiến trên thế giới. Triển khai thực hiện Chiến lược trên, mạng lưới quan trắc và công nghệ quan trắc đo đạc đã và đang từng bước được hiện đại hóa. Đài đã và đang mạnh dạn tiến hành một số nghiên cứu nhằm nâng cao chất lượng phục vụ của mạng lưới trạm quan trắc khí tượng, thủy văn, môi trường. Trong số những nghiên cứu đó có Nghiên cứu cải tiến hệ thống truyền tin và tự động hóa cho các thiết bị đo mưa, gió thủ công.

Từ khóa: Tích hợp thiết bị thủ công; Bán tự động thiết bị đo mưa; Đo gió.

\section{Mở đầu}

Hiện nay, đa phần các nước có hệ thống các trạm khí tượng tự động với độ chính xác cao và cấu hình linh hoạt giúp các cơ quan khí tượng thu thập số liệu kịp thời cho các mô hình dự báo. Việc ứng dụng các công nghệ và thiết bị tiên tiến trong đo đạc thu thập số liệu đo gió, đo mưa hiện đại, thu thập số liệu theo thời gian thực đã nâng cao chất lượng dự báo và phòng tránh, giảm nhẹ thiên tai mang lại phát triển kinh tế xã hội bền vững.

Công nghệ thông tin liên lạc với những tiến bộ vượt bậc đã được sử dụng rộng rãi trong Ngành KTTV trên thế giới. Mạng viễn thông toàn cầu (GTS) của Tổ chức Khí tượng thế giới đã được cải tổ và ứng dụng những công nghệ mới bảo đảm liên lạc tối ưu giữa các trung tâm KTTV trên thế giới. Các trung tâm khí tượng thế giới và khu vực đều có nhiều đường truyền băng thông rộng và tốc độ cao. Những công nghệ viễn thông mới như Internet, vi ba và vệ tinh thu thập được số liệu tức thời từ trạm KTTV ở bất kỳ địa điểm nào. Công nghệ thông tin liên lạc mới cũng cho phép cung cấp thông tin KTTV cho nhiều đối tượng kịp thời với nhiều dạng thức khác nhau từ truyền thống đến dạng số hoá.

Đến năm 2020, mạng lưới quan trắc khí tượng thủy văn có mật độ trạm tương đương với các nước phát triển và tự động hóa trên $90 \%$ số trạm quan trắc, đồng thời tăng cường các hệ thống đo đạc từ xa, bảo đảm theo dõi liên tục các biến động về thời tiết, khí hậu, tài nguyên nước, đáp ứng đầy đủ dữ liệu cho dự báo khí tượng thủy văn theo phương pháp tiên tiến và các nhu cầu khác. Hiện đại hóa và tự động hóa hệ thống thông tin truyền dẫn số liệu 
khí tượng thủy văn, nâng cao tốc độ và mở rộng băng thông, đáp ứng yêu cầu phát triển công nghệ dự báo và trao đổi số liệu trong và ngoài ngành. Điều này là cơ sở để việc đầu tư cho nghiên cứu khoa học được đẩy mạnh [1].

Nghiên cứu Modem truyền tin hệ thống đo gió từ loại máy đo gió Young 26700 và 26800 của Mỹ được sử dụng cho các trạm Khí tượng; với tính năng ban đầu là ghi số liệu vào Datalogger. Hàng tháng cán bộ rút số liệu và dùng phần mềm khai thác số liệu, nghiên cứu đã truyền tin và khai thác số liệu từ xa. Kết quả thật đáng khích lệ, làm tiền đề cho những nghiên cứu tiếp theo và là một bước phát triển mới trong ngành Khí tượng Thủy văn. Tuy nhiên với hạ tầng công nghệ lúc bấy giờ còn hạn chế, việc truyền tin bằng SMS với giá thành khá cao, tần suất truyền tin thưa; chưa đáp ứng được nhu cầu thông tin nhanh, chính xác phục vụ cho công tác phòng chống thiên tai [2].

Như vậy, với khoảng thời gian truyền tin 1 giờ một lần cho đến nay là chưa phù hợp theo Quyết định số 357/QĐ-KTTVQG ngày 21 tháng 7 năm 2014 về việc “ Ban hành quy định dạng file số liệu, tần suất đo và truyền số liệu trạm khí tượng thủy văn tự động” [3]. Giá thành của gói tin nhắn quá cao, theo thống kê của Kế hoạch tài chính, bình quân phải chi trả cho một sim là 280.000 đ/ tháng. Cũng như qua quá trình theo dõi giám sát, thiết bị đầu cuối trước khi vào Sever là Modul nhận, thường xuyên bị mất kết nối do chủ quan người dùng. Mặt khác với nghiên cứu này, thiết bị Sensor và Datalogger máy đo mưa SL31 hoàn toàn độc lập, không thể dùng chung với bất cứ thiết bị nào khác. Chính vì vậy cũng cần nghiên cứu theo phương thức truyền mới; phù hợp với sự phát triển của hạ tầng công nghệ mới.

Hiện nay 184 trạm Khí tượng, mỗi trạm có thiết bị đo mưa theo nguyên lý chao lật cả sử dụng và dự phòng bình quân mỗi Trạm có hai thiết bị. Như vậy khoảng 372 máy đo mưa trên mạng lưới, hàng năm việc thay thế linh kiện như đồng hồ máy mưa, vỉ mạch đo mưa, dây cuzoa là khá tốn kém. Đặc biệt phụ thuộc vào thời tiết của từng địa phương do đó dây cuzoa rất hay bị hỏng, đặc biệt dây cuzoa lại không để lâu được (tự mục ải). Trong khi đó thiết bị vẫn chỉ là dùng thủ công, không thể cung cấp thông tin nhanh phục vụ công tác dự báo, cảnh báo sớm. Đối với máy gió Young cũng vậy, loại máy này tương đối đắt, do đó bình quân mỗi Trạm có 01 máy. Thường dùng khai thác số liệu tại chỗ, dùng phần mềm kết xuất số liệu báo cáo. Với cơ cấu cấp quản lý hiện nay, các máy dự phòng tại Trạm là không thể trang bị đầy đủ; ngay cả Đài KTTV tỉnh, Đài khu vực cũng vậy. Do vậy việc khi máy hỏng việc cán bộ kỹ thuật của Đài khu vực đi thay thế là vô cùng vất vả. Đặc biệt các Đài có khu vực quản lý rộng lớn.

Việc tận dụng tối đa máy thiết bị đang có trên mạng lưới trạm là hết sức cần thiết, có thể tiết kiệm được đáng kể một nguồn ngân sách đầu tư thiết bị hàng năm. Nghiên cứu sử dụng phương pháp thu thập thông tin, phương pháp kế thừa, phương pháp phân tích, tổng hợp, phương pháp chuyên gia, phương pháp xử lý số liệu. Mục tiêu của nghiên cứu nhằm cải tiến và tích hợp được hệ thống truyền tin cho thiết bị đo gió Young và mưa SL-1, SL31 theo phương thức GPRS/3G. Áp dụng thử nghiệm tại 02 trạm khí tượng Nam Định và Ninh Bình.

\section{Phương pháp nghiên cứu và tài liệu thu thập}

Trong bối cảnh kinh phí hàng năm giảm, nhưng nhu cầu truyền số liệu phải nhanh chóng kịp thời, do đó cần khai thác tối đa thiết bị đang có như máy gió Young được trang bị trước đây, máy đo mưa SL-1, SL3-1 hiện đang được các Trạm sử dụng, phương thức truyền tin theo phương pháp thủ công. Cùng với sự phát triển của công nghệ thông tin với rất nhiều phương thức truyền tin nhanh chóng và phổ biến như GPRS, $3 \mathrm{G}$, việc cải tiến phương thức truyền tin theo thủ công sang tự động giúp thu thập số liệu được nhanh, chính xác góp phần phòng, chống thiên tai hiệu quả là cần thiết. Vì vậy, nghiên cứu đặt ra mục tiêu "Cải tiến và tích hợp được hệ thống truyền tin cho thiết bị đo gió Young và mưa SL-1, 
SL-3 theo phương thức GPRS/3G; đồng thời sẽ thử nghiệm tại trạm khí tượng Nam Định và Ninh Bình để hoàn thiện thiết bị.

\subsection{Phưong pháp thu thập thông tin}

Định dạng file số liệu ra sao là một phần quan trọng trong công tác truyền tin và tiếp nhận thông tin; chính vì vậy số liệu truyền về được lựa chọn dựa trên Quyết định số 357/QĐ-KTTVQG ngày 21 tháng 7 năm 2014 của Trung tâm Khí tượng Thủy văn quốc gia (nay là Tổng cục Khí tượng Thủy văn) về việc Ban hành quy định định dạng file số liệu, tần suất đo và truyền số liệu trạm khí tượng thủy văn tự động. Cấu trúc file số liệu đo chi tiết tại phụ lục kèm theo và được thể hiện tại bảng 1 .

Bảng 1. Cấu trúc file số liệu đo khí tượng tự động.

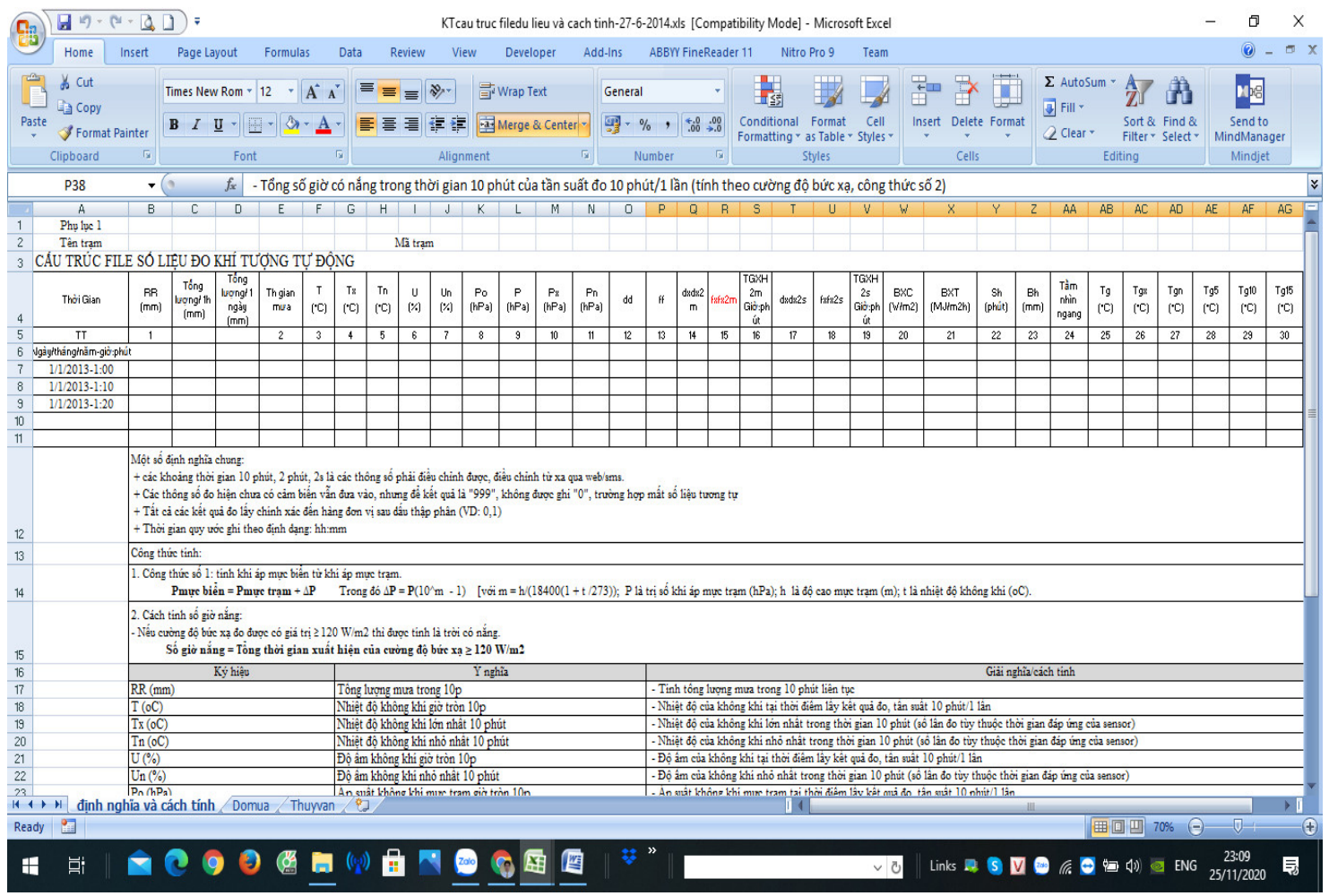

Trong đó RR là tổng lượng mưa trong 10 phút $(\mathrm{mm})$; dd là hướng gió giờ tròn 10 phút (độ); $\mathrm{dxdx} 2 \mathrm{~m}$ là hướng gió của vận tốc Max 2 phút trong 10 phút (độ); fxfx $2 \mathrm{~m}$ là vận tốc gió lớn nhất 2 phút trong 10 phút (m/s); TGXH $2 \mathrm{~m}$ là thời gian xuất hiện vận tốc gió Max 2 phút trong 10 phút (phút); dxdx2s là hướng gió của vận tốc Max 2 giây trong 10 phút (độ); fxfx $2 \mathrm{~s}$ là vận tốc gió lớn nhất 2 giây trong 10 phút $(\mathrm{m} / \mathrm{s})$; TGXH $2 \mathrm{~s}$ Thời gian xuất hiện vận tốc gió Max 2 giây trong 10 phút (giây).

\subsection{Phwơng pháp kế thùra}

Mục tiêu của nghiên cứu nhằm cải tiến và tích hợp được hệ thống truyền tin cho thiết bị đo gió Young và mưa SL-1, SL3-1 theo phương thức GPRS/3G. Hệ thống truyền tin sau cải tiến sẽ được áp dụng thử nghiệm tại 02 trạm khí tượng Nam Định và Ninh Bình.

Để phục vụ công tác điều tra cơ bản và dự báo KTTV, Đài ĐBBB đang quản lý và vận hành mạng lưới điều tra cơ bản gồm 14 trạm khí tượng, 53 điểm đo mưa nhân dân (năm 201853 điểm này đã được tự động hóa do đơn vị bên ngoài đầu tư), 21 điểm đo mưa tự động do Dự án 1000 năm Thăng Long Hà Nội và Dự án Phát triển mạng lưới Trạm. Trong đó Đài ĐBBB có 17 máy đo gió Young thì vẫn có 06 máy truyền tự động bằng tin nhắn 
SMS đó là: KT Văn Lý (2), TV Phú Lễ, KT Ninh Bình, TV Như Tân, KT Nho Quan và 02 máy truyền bằng GPRS: KT Thái Bình, TV Ba Lạt, Hà Đông, KT Nam Định là do đầu tư về sau này. Đồng thời có 21 điểm đo mưa tự động truyền bằng tin nhắn SMS (năm 2018 đã thay bộ chuyển đổi thành truyền GPRS. Ngoài ra còn có 3 trạm thời tiết tự động: Ba Vì, Chí Linh, Văn Lý.

Đặc biệt trạm KT Nam Đinh được đầu tư mới trạm tự động đo gió, xong đang sử dụng Datalogger Cambeo C1000, không có màn hình hiển thị số liệu tại Trạm, bộ truyền tin được lắp tại cột đo gió, mà chỉ truyền về máy chủ. Điều này rất khó khăn cho các sự cố, cán bộ không thể theo dõi số liệu được. Đối với trạm Ninh Bình, máy đo gió vẫn truyền bằng SMS số liệu gió, còn số liệu mưa của Trạm vẫn là băng giấy tự ghi. Mặc dù đã được đầu tư 01 máy mưa tích hợp nhiệt mới, xong số liệu truyền về phục vụ Dự báo, còn đối với địa phương chưa khai thác được.

Với yêu cầu hiện đại hóa ngành khí tượng thủy văn theo Quyết định Số: 929/QĐ-TTg ngày 22 tháng 06 năm 2010 của Thủ tướng Chính phủ. Đến năm 2020, mạng lưới quan trắc khí tượng thủy văn có mật độ trạm tương đương với các nước phát triển và tự động hóa trên $90 \%$ số trạm quan trắc, đồng thời tăng cường các hệ thống đo đạc từ xa, bảo đảm theo dõi liên tục các biến động về thời tiết, khí hậu, tài nguyên nước, đáp ứng đầy đủ dữ liệu cho dự báo khí tượng thủy văn theo phương pháp tiên tiến và các nhu cầu khác. Hiện đại hóa và tự động hóa hệ thống thông tin truyền dẫn số liệu khí tượng thủy văn, nâng cao tốc độ và mở rộng băng thông, đáp ứng yêu cầu phát triển công nghệ dự báo và trao đổi số liệu trong và ngoài ngành.

Việc tận dụng tối đa máy thiết bị đang có trên mạng lưới trạm là hết sức cần thiết, có thể nói sẽ tiết kiệm được đáng kể một nguồn ngân sách đầu tư thiết bị hàng năm, mà số liệu vẫn đảm bảo theo Quyết định số 357/QĐ-KTTVQG ngày 21 tháng 7 năm 2014 về việc “ Ban hành quy định dạng file số liệu, tần suất đo và truyền số liệu trạm khí tượng thủy văn tự động".

Chính vì vậy, nghiên cứu này đã kế thừa thành tựu nghiên cứu truyền tin bằng SMS để cải tiên phương pháp truyền tin thành GPRS/3G.

\subsection{Phuơng pháp phân tích, tổng hợp}

Thiết bị đo mưa: bao gồm hai bộ phận chính đó là sensor chao lật SL-1; SL3-1 của Trung Quốc sản xuất và bộ hiển thị số hoặc ghi trên băng giấy (giản đồ mưa). Sensor sử dụng côc đo, khi lượng mưa đủ theo tỷ lệ $0,1 \mathrm{~mm}$ theo độ phân giải, khi đó chao lật sẽ đếm số lần chao lật tương ứng theo tính toán và được vi mạch tại bộ hiển thị hay ghi trên giản đồ để ghi giá trị mưa. Với nguyên lý trên các nghiên cứu trước đây đã lấy sensor SL3-1 để tích hợp, tính và truyền số liệu bằng SMS về Sever (Hình 1). Để nguyên lý này hoạt động được, cần một nguồn điện nuôi để thực hiện phép đo.

Vậy tín hiệu thực hiện phép đo là gì? Thì đây là tín hiệu sung vuông, điều này chúng ta có thể tích hợp để dùng tính và truyền số liệu theo phương pháp GPRS/3G thay cho phương thức truyền SMS mà nghiên cứu trước thực hiện? Liệu rằng, vừa sử dụng lấy tín hiệu để truyền đồng thời lấy tín hiệu để ghi trên giản đồ được hay không?

Về nguyên lý điện, hoàn toàn thực hiện được; xong liệu có xuất hiện sự sung điện trong khi lấy tín hiệu không? Điều này hoàn toàn có thể xảy ra. Từ đó cần những bước tính kỹ lưỡng để khi kết nối, không có sự xung điện xẩy ra. Vậy khi hệ thống ghi trên giản đồ nhảy sẽ xuất hiện điện từ, liệu có làm hệ thống sung nhảy đúp hoặc nhiễu tín hiệu?

Bài toán cần tính là nghiên cứu cần có chống nhiễu tín hiệu, từ đó có thể khảng định, hoàn toàn thực hiện được.

Tổng hợp phân tích trên để thiết kế tính toán, lựa chọn linh kiện và thực hiện nghiên cứu bộ truyền tin, từ đó dễ dàng thay thế nâng cấp theo yêu cầu và ứng dụng thực tế. Giá thành chỉ bằng $30 \%$ giá thành nhập ngoại. 


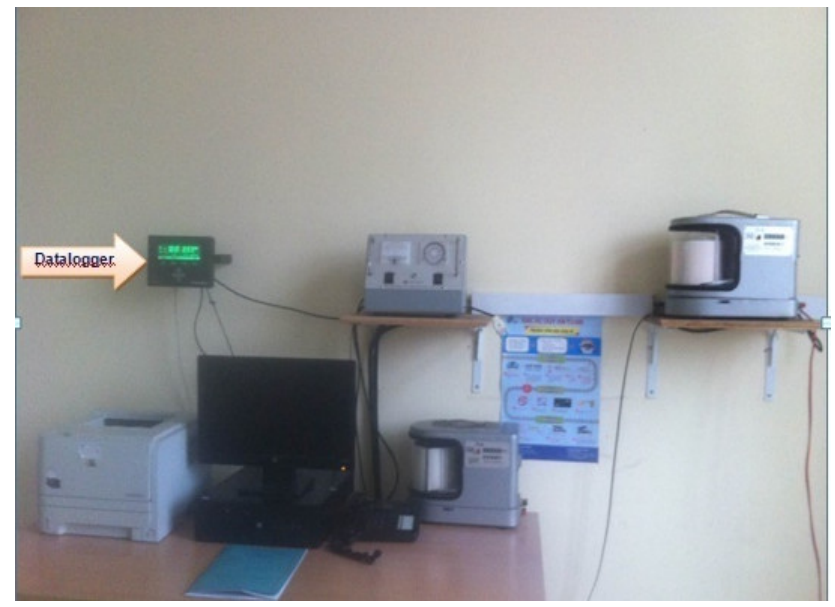

Hình 1. Bộ đo mưa SL3-1.

Thiết bị đo gió: bao gồm hai bộ phận chính là sensor đo gió Young 05103 (trạm Ninh Bình, Nam Định) (Hình 2) và Datalogger 26700 kết hợp với bộ xử lý truyền tin theo phương thức SMS. Điều này cho thấy số liệu đã được truyền tin, vậy với sự phát triển của mạng viễn thông, công nghệ; chúng ta hoàn toàn có thể cải tiến nâng cấp truyền tin theo phương thức GPRS/3G được.

Như phân tích ở trên, liệu rằng có sự gây nhiễu tín hiệu khi thực hiện sử dụng cả hai phương pháp cùng lúc hay không? Theo nghiên cứu tín hiệu ra của sensor thì đối với máy gió Young tín hiệu ra là tín hiệu điện, nhà sản xuất tùy theo nhu cầu sử dụng đã thiết kế bộ chuyển đổi tín hiệu điện thành nhiều dạng khác nhau như: tín hiệu sin vuông, sin sung, điện 0-5v; 4-20map... Vậy xác định tốc độ thuộc dòng tín hiệu gì, hướng thuộc dòng tine hiệu gì để nghiên cứu tính toán các bài toán tương ứng.

Theo nguyên lý điện, hoàn toàn lấy tín hiệu để phân chia theo các đường đi khác nhau và liệu rằng có tính đến suy hao tín hiệu hay không?

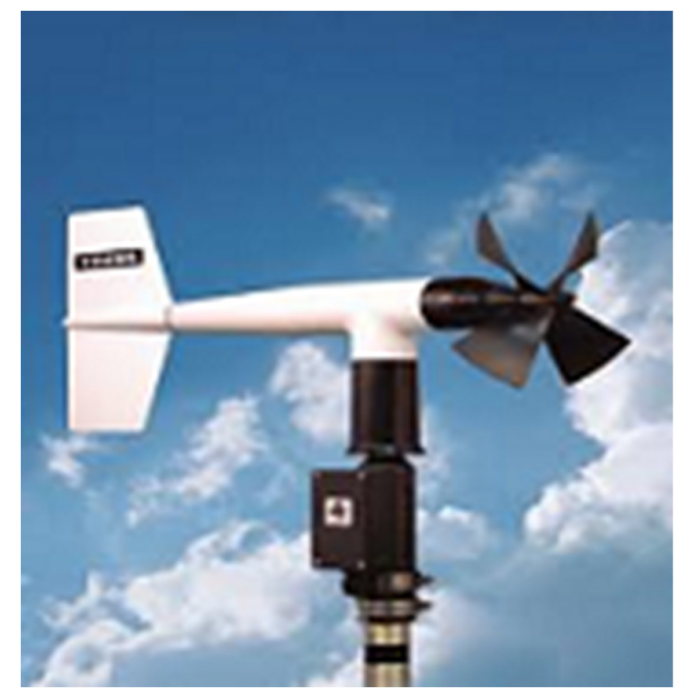

Hình 2. Sensor gió Young.

Tổng hợp phân tích ở trên, nghiên cứu cần có các bước tính toán, thiết kế, lựa chọn linh kiện phù hợp và thực hiện nghiên cứu (Hình 3 ). 

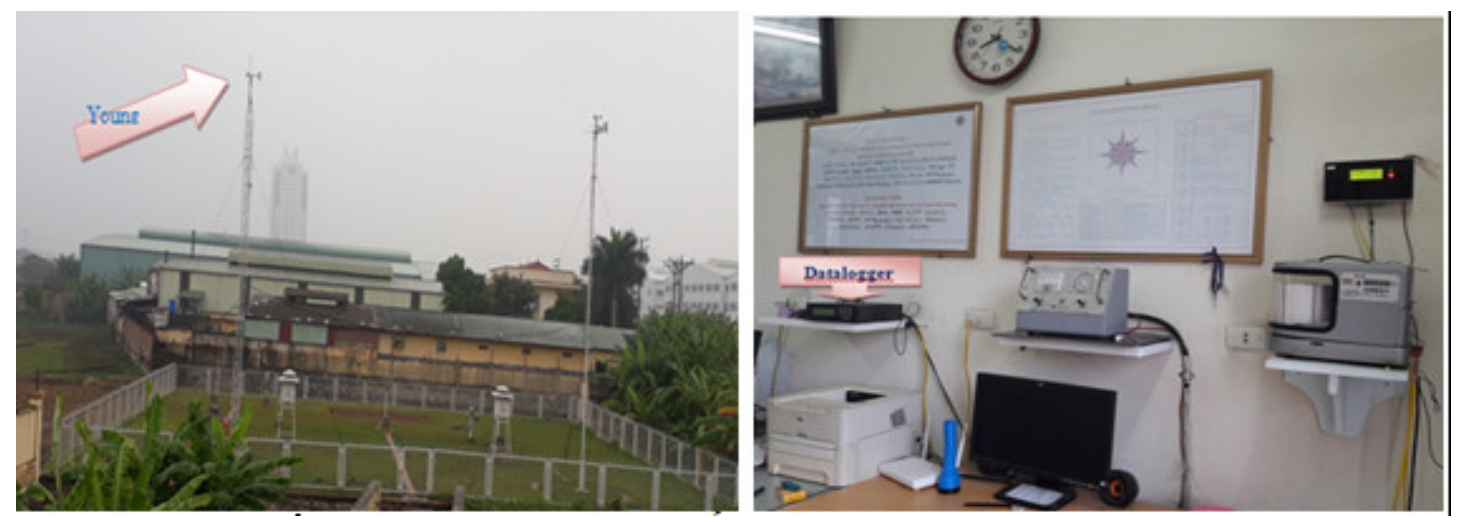

Hình 3. Bộ đo gió.

\subsection{Phương pháp chuyên gia}

Nghiên cứu có liên quan đến kỹ thuật điện tử, tín hiệu, các thiết bị điện ngoại vi khác làm nhiễu tín hiệu... Ngoài ra các trạm và thiết bị phải họat động trong các môi trường nhiệt đới khắc nghiệt như độ ẩm cao, mưa, sét, ngập nước,.... Chính vì vậy, các thiết bị chế tạo phải rất bền, ổn định, có tính dự phòng cao và ít đòi hỏi bảo trì. Thiết bị được chế tạo cần có những chuyên gia có trình độ chuyên môn cao để thực hiện thiết kế bản vẽ về ghép nối (Hình 4 và hình 5).

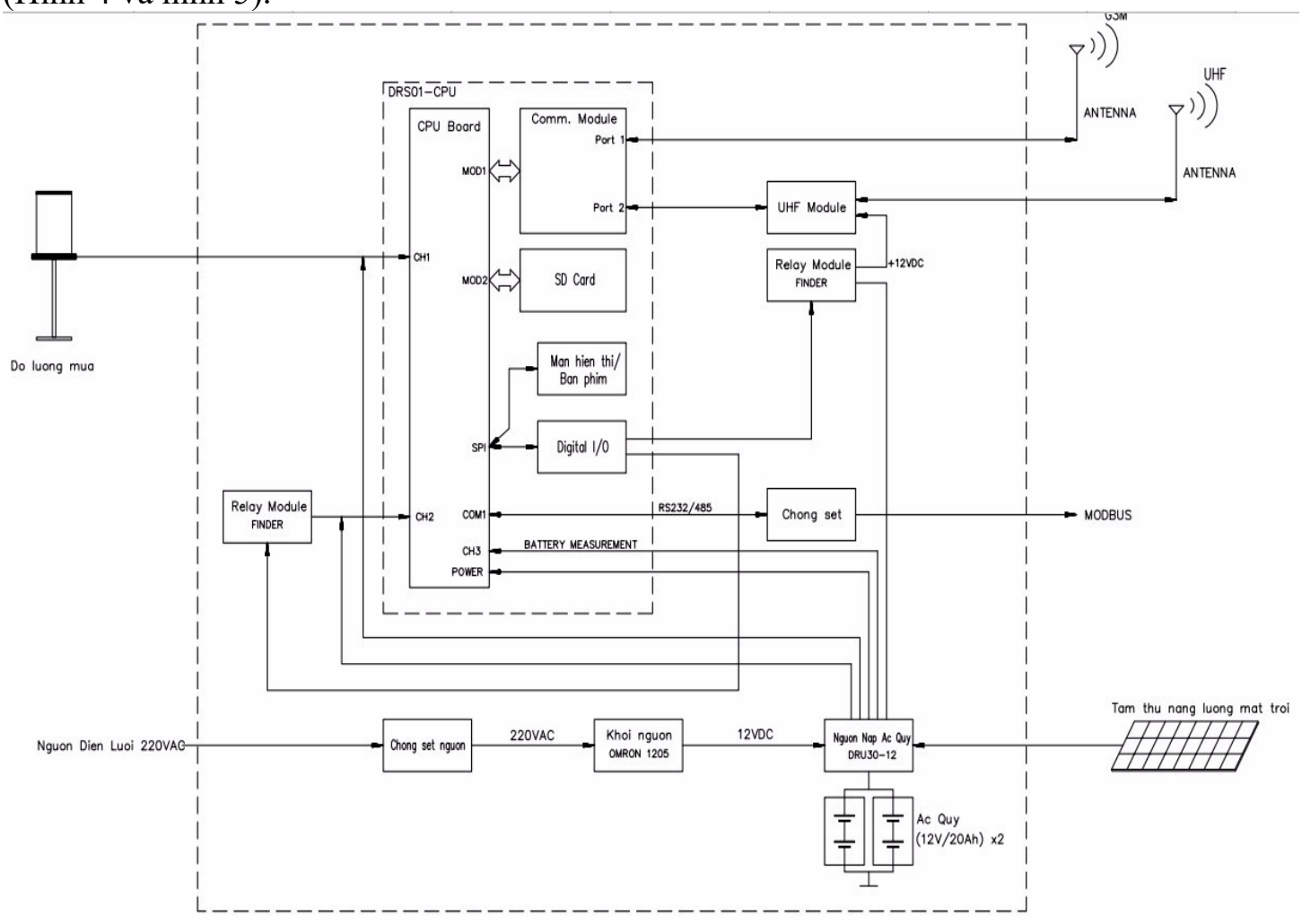

Hình 4. Sơ đồ thiết kế tổng thể các thành phần của trạm đo mưa. 


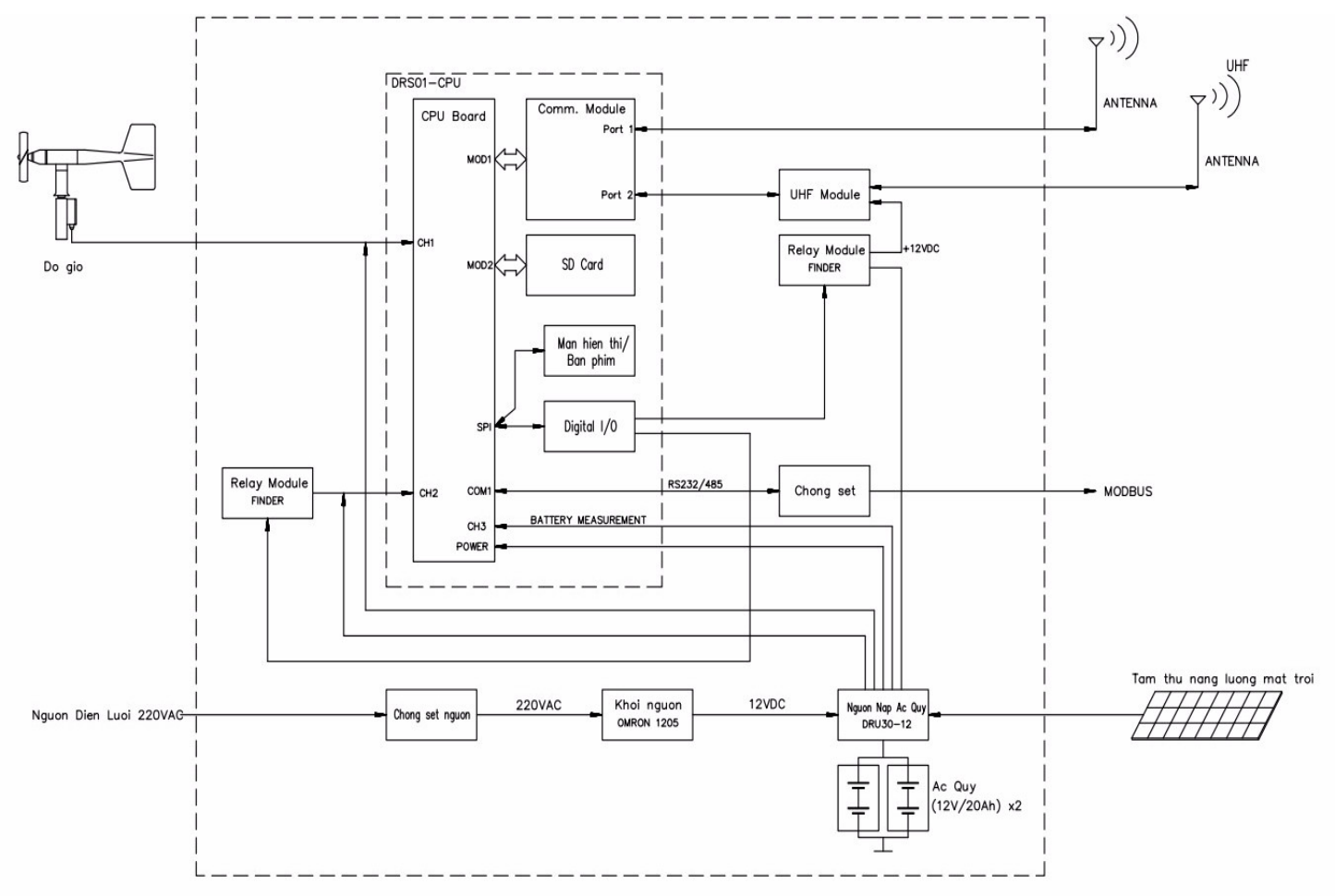

Hình 5. Sơ đồ thiết kế tổng thể các thành phần của trạm đo gió.

Hình 6 và hình 7 là sơ đồ ghép nối của trạm đo DRS01 với các module truyền thông và sơ đồ nguyên lý của mạch truyền thông.

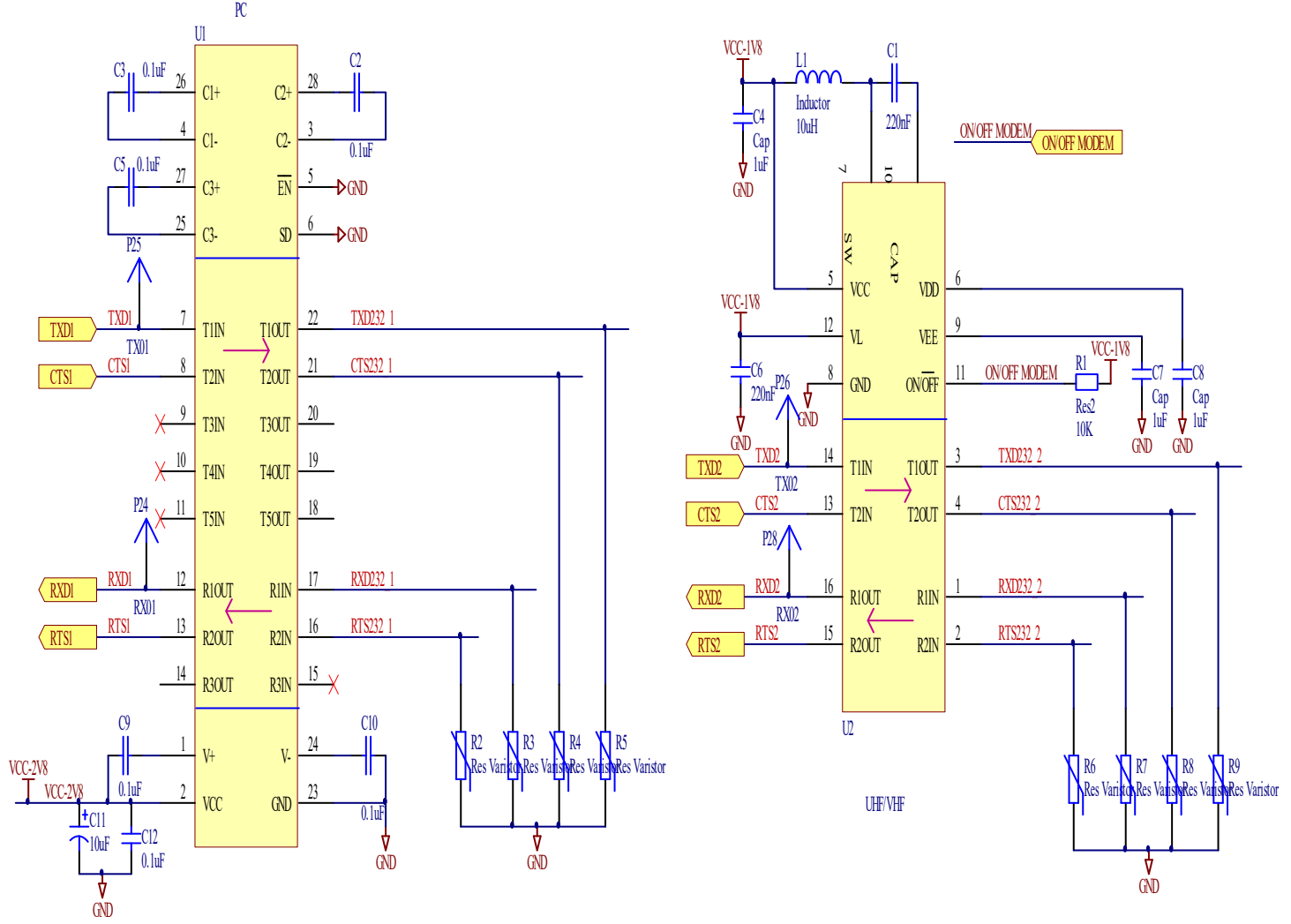

Hình 6. Sơ đồ nguyên lý mạch truyền thông. 


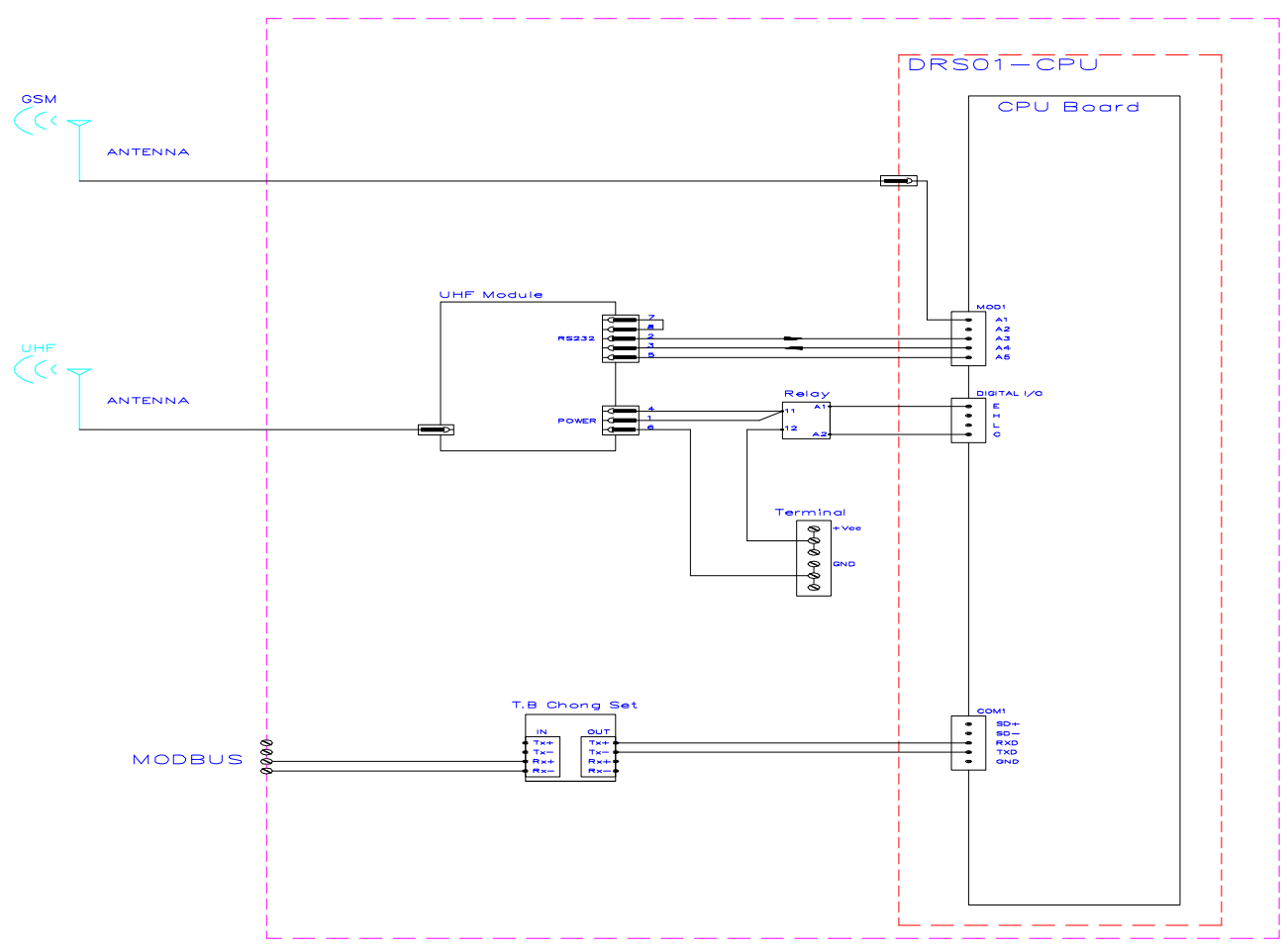

Hình 7. Sơ đồ thiết kế đầu nối khối CPU và khối truyền thông.

\subsection{Phưong pháp xủ lý số liệu}

Đối với thiết bị thủ công như máy mưa SL3-1, tín hiệu được đấu nối song song với bộ hiển thị, giản đồ tự ghi có sẵn. Trong nghiên cứu có tính tới việc sung tín hiệu bằng phương pháp cách ly tín hiệu bởi hoạt động của bản mạch điện tử máy mưa SL3-1. Tín hiệu máy mưa là tín hiệu sung, do vậy việc tính toán số liệu mưa phù hợp với giá trị ghi trên giản đồ.

Đối với máy gió Young Đầu vào tương tự của trạm đo là tín hiệu 4-20mA từ đầu đo gió. Để thực hiện đo các tín hiệu 4-20mA, các thiết bị đi hiện nay thường sử dụng ADC $\geq 16$ bit, nhiễu thấp, tiết kiệm năng lượng, ít chịu ảnh hưởng của nhiệt độ... Đồng thời $\mathrm{ADC}$ được sử dụng cần tương thích với các giao tiếp sã̃n có của CPU.

Dựa trên những yêu cầu này, nghiên cứu sử dụng $\mathrm{IC}$ chuyển đổi $\mathrm{ADC}$ là $\mathrm{ADC} 7793$. Các đặc điểm kỹ thuật của $\mathrm{ADC} 7793$ như sau: độ phân giải 24 bit, công suất nhỏ, mức nhiễu thấp, nó là một $\mathrm{ADC} \Sigma-\Delta$ với 3 đầu vào vi sai, phù hợp với các thiết kế đa kênh, dùng trong các phép đo tín hiệu analog cần độ chính xác cao. Trong IC có chứa một bộ khuếch đại dụng cụ, do đó $\mathrm{IC}$ vẫn có thể đo được tín hiệu biên độ nhỏ. Tốc độ xuất dữ liệu từ mỗi kênh biến thiên từ $4.17 \mathrm{~Hz}$ đến $500 \mathrm{~Hz}$.

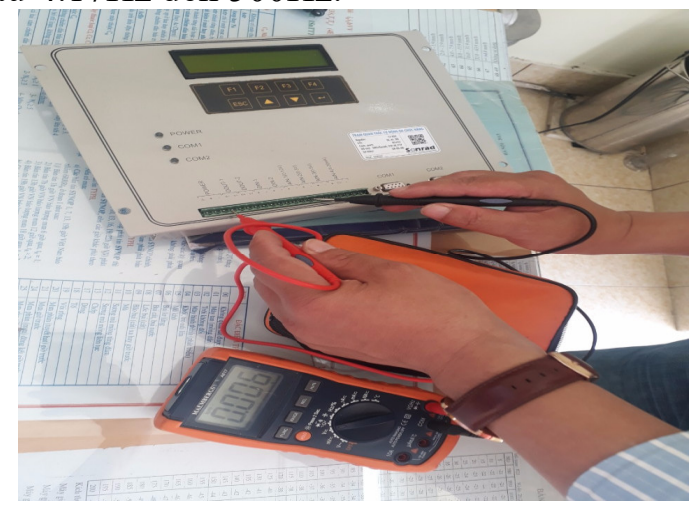

Hình 8. Thực hiện đo các chân tín hiệu. 
Cấu trúc số liệu trạm thử nghiệm nghiên cứu bởi 02 yếu tố, do đó bảng cấu trúc được rút gọn trong hình 10 . Vì vậy, số liệu hiển thị tại màn hình trạm Ninh Bình, Nam định được hiểu ý nghĩa theo đúng quy định và được thông qua các phím chức năng để chuyển đổi chức năng đọc số liệu. Số liệu được truyền về Sever lưu dữ phục vụ công tác giám sát, khai thác số liệu thuận tiện, dễ sử dụng. Số liệu đã được chuẩn hóa $(\mathrm{QA} / \mathrm{QC})$ trước khi truyền về theo cấu trúc Quyết định số 357/QĐ-KTTVQG ngày 21 tháng 7 năm 2014 [3].

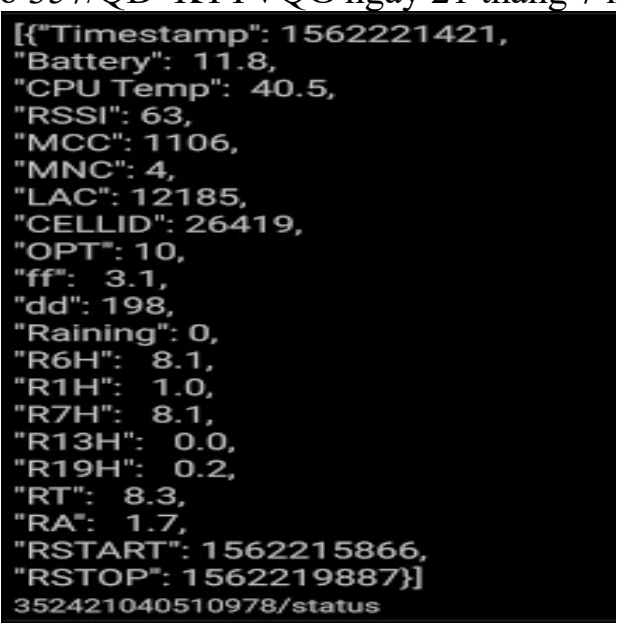

Hình 9. Phân tích ký hiệu truyền thống.

Trong đó Timestamp: Thời gian; Battery: Ăc quy; CPU Temp: Nhiệt độ vi mạch; RSSI: Chất lượng sóng; MCC: Mã cột phát sóng của nhà mạng; MNC: Mức sóng tại vị trí truyền tin; CELLID: Mã quy ước trạm; OPT: obs 10 phút; ff: Tốc độ gió trung bình trong 2 phút; dd: Hướng gió tương ứng ff; Raining: Mưa 24 giờ; R6H: mưa 6 giờ; $\mathrm{R} 1 \mathrm{H}$ : mưa tích lũy obs 1h; R7H: mưa tích lũy obs $7 \mathrm{~h}$; R13H: mưa tích lũy obs $13 \mathrm{~h}$; R19H: mưa tích lũy obs 19h; RSTART: Xác định thời gian bắt đầu mưa; RSTOP: Xác định thời gian kết thúc mưa; fxfx2m: Gió obs 10 phút; dxdx2m: Hướng tương ứng; TGXH2m: Thời gian xuất hiện; fxfx2s: Gió max trong 10 phút; $\mathrm{dxdx} 2 \mathrm{~s}$ : Hướng tương ứng; TGXH2s: Thời gian xuất hiện.

\section{Kết quả và thảo luận}

\subsection{Kết quả kiểm định số liệu quan trắc tại trạm thử nghiệm}

Đánh giá kết quả kiểm định số liệu quan trắc tại 02 trạm khí tượng Ninh Bình và Nam Định cho kết quả khá tốt. Số liệu được hiển thị trên màn hình rõ nét, thuận tiện cho quan trắc viên theo dõi số liệu. Máy đo mưa SL3-1 trạm Khí tượng Ninh Bình chạy song song giữa truyền tự động và hiển thị trên màm hình, chạy trên giản đồ tự ghi bình thường. Đây là cơ sở để đánh giá sản phẩm và là tiền đề phục vụ đánh giá chất lượng hoạt động, số liệu tự động. Máy gió Young sử dụng Datalogger 26700 và Modem truyền tin cũ vẫn hoạt động bình thường, số liệu được truyền tin theo phương thức $3 \mathrm{G} / 4 \mathrm{G}$ và có khả năng nâng cấp lên 5G. Đây là cơ sở so sánh số liệu giữa 2 phương thức cũ và mới. Máy đo mưa SL3-1 trạm Khí tượng Nam Định chạy song song giữa truyền tự động và hiển thị trên màm hình, chạy trên giản đồ tự ghi bình thường. Đây là cơ sở để đánh giá sản phẩm và là tiền đề phục vụ đánh giá chất lượng hoạt động, số liệu tự động. Máy gió Young 05103 trạm Nam Định sử dụng Datalogger CR1000 lắp tại vườn khí tượng vẫn hoạt động bình thường, được kết nối truyền dữ liệu vào Trạm để theo dõi và truyền về Sever ổn định. Kết quả kiểm định tại trạm Khí tượng Ninh Bình được thể hiện trên các hình 10 đến hình 12. 


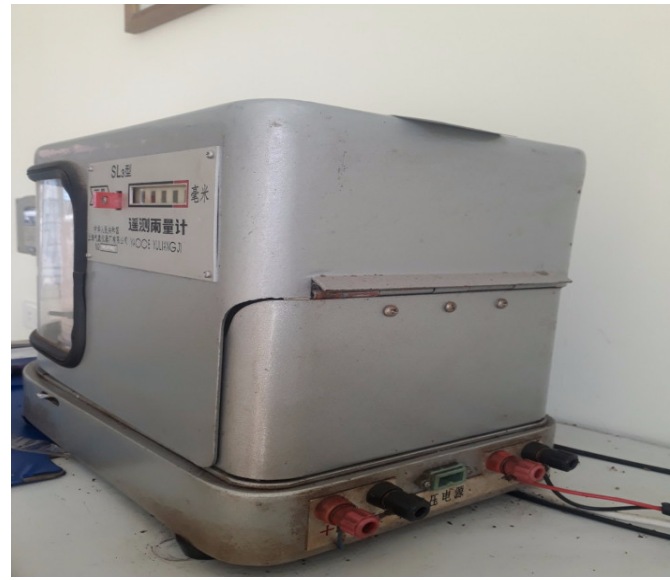

(a)

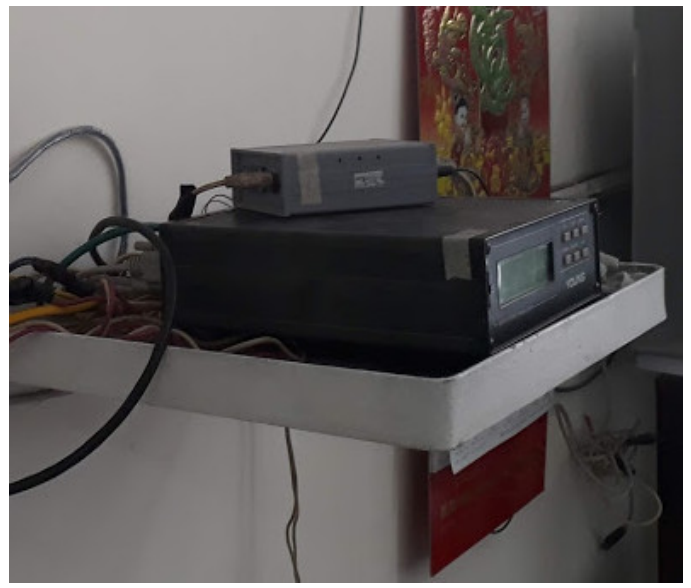

(b)

Hình 10. Hiện trạng trạm Khí tượng Ninh Bình: (a) Bộ hiển thị, ghi giản đồ mưa SL3-1 Ninh Bình; (b) Datalogger 26700 và modem truyền tin SMS.

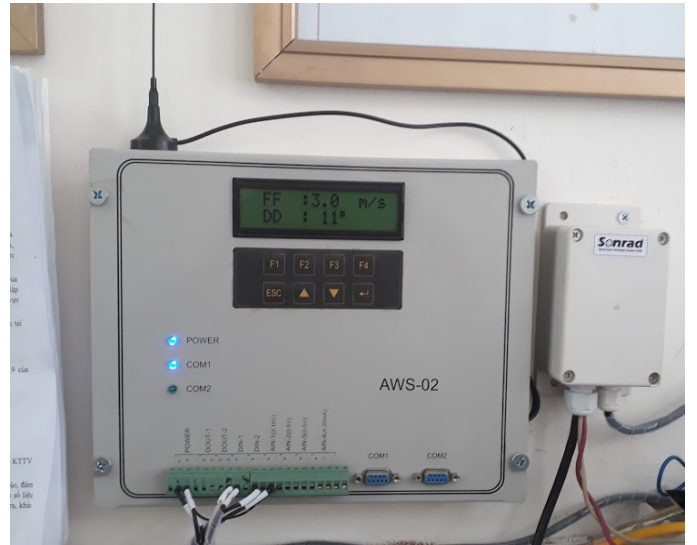

(a)

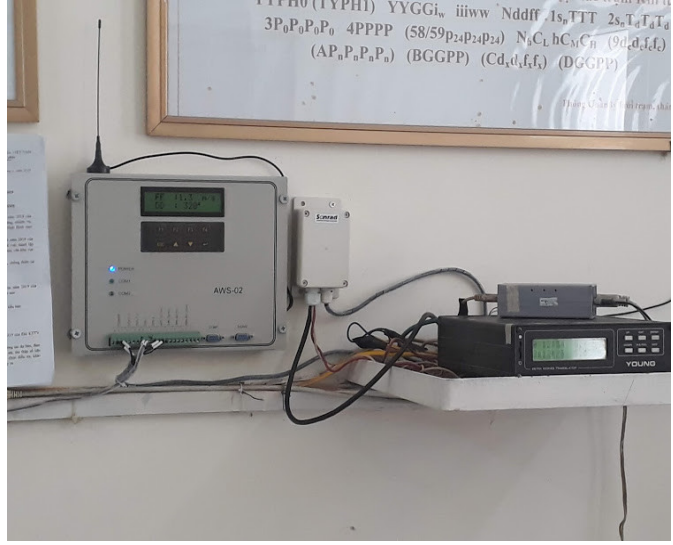

(b)

Hình 11. Kết quả hiển thị trạm Khí tượng Ninh Bình: (a) Bộ chuyển đối sau khi hoàn thành; (b) Bộ chuyển đối được kết nối với hệ thống gió cũ.

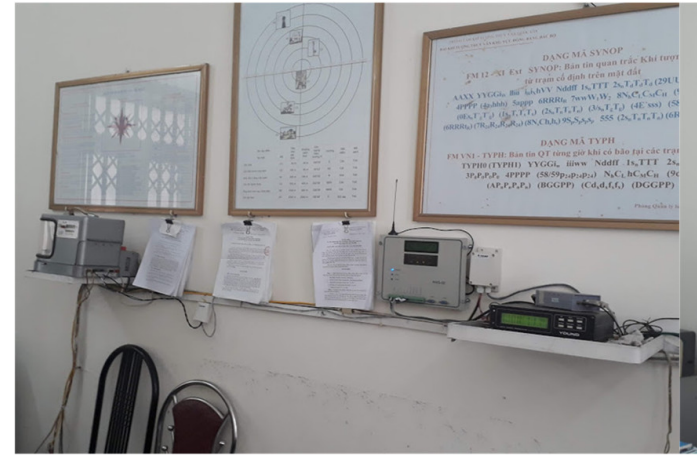

(a)

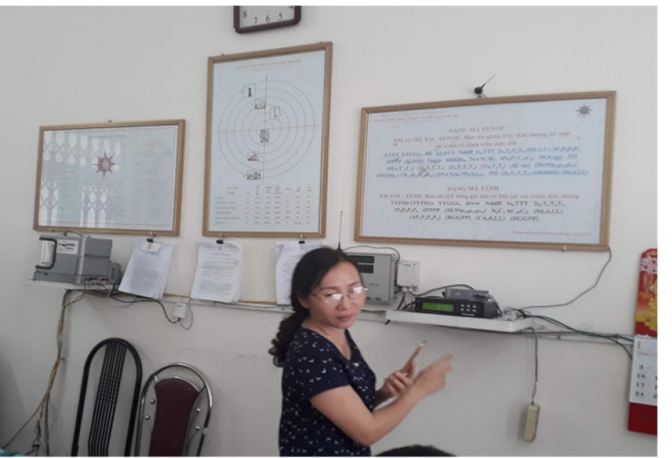

(b)

Hình 12. (a) Tổng thể đấu nối trạm Khí tượng Ninh Bình; (b) Kiểm tra số liệu trạm Khí tượng Ninh Bình.

Kết quả kiểm định tại trạm Khí tượng Nam Định được thể hiện trên các hình 15. 


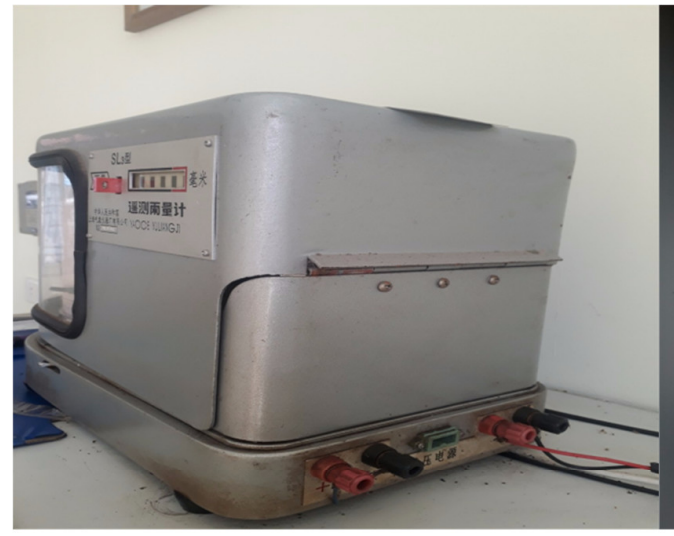

(a)

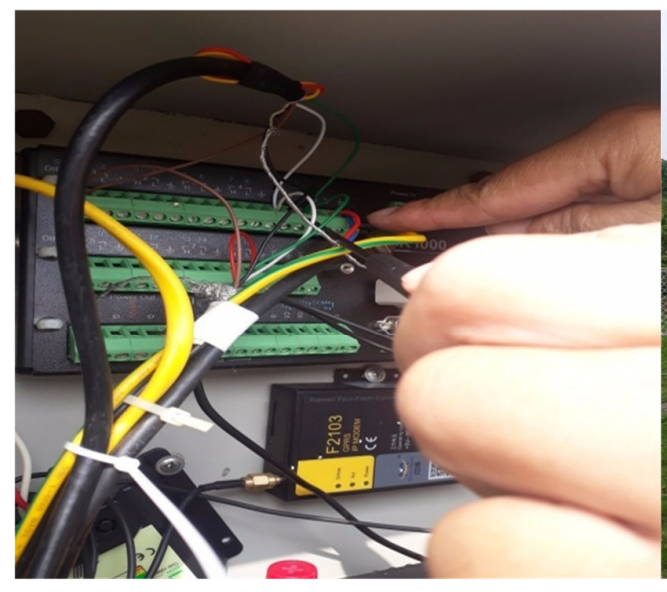

(c)

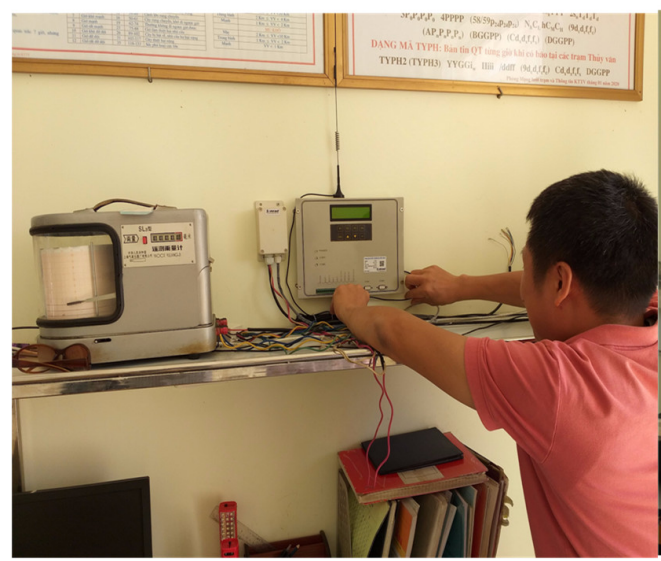

(e)

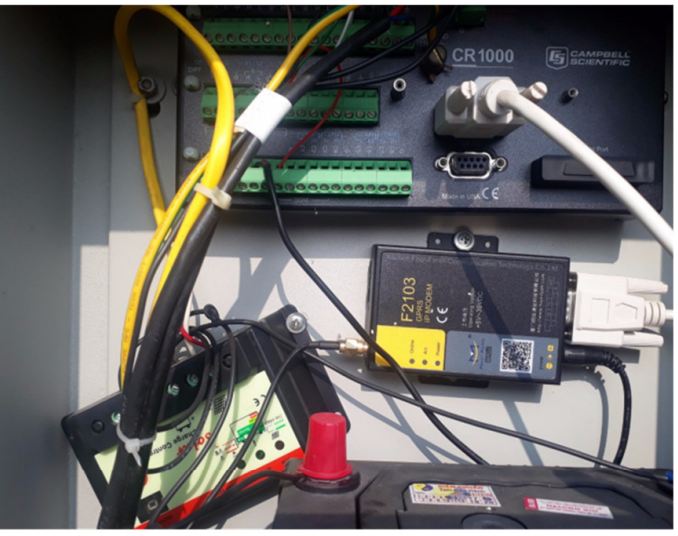

(b)

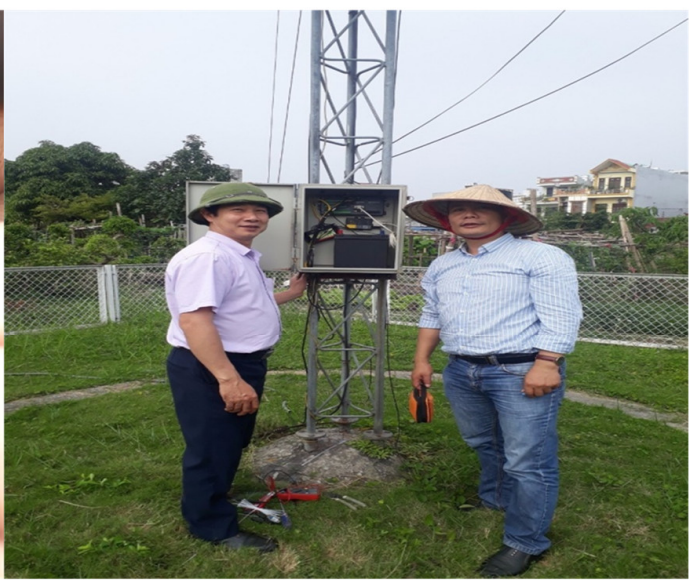

(d)

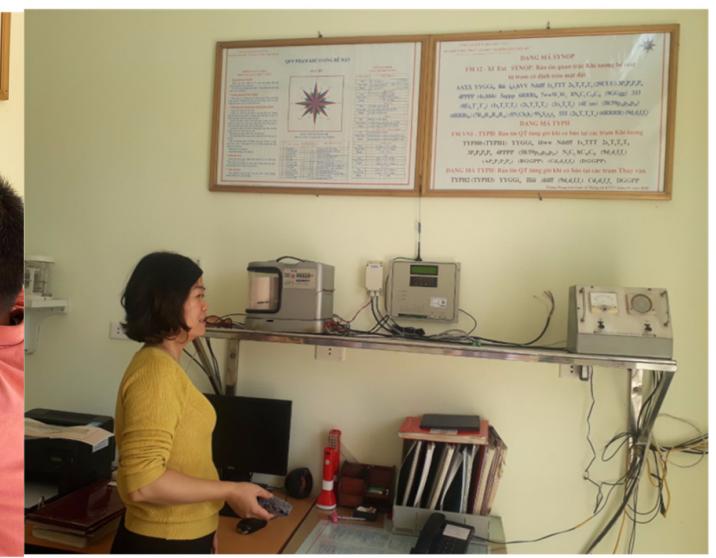

(f)

Hình 15. (a) Bộ hiển thị, ghi giản đồ mưa SL3-1; (b) Hệ thống đo gió cũ; (c) Đấu nối máy gió; (d) Kết quả đấu nối máy gió; (e) Đấu nối máy gió, mưa trạm KT; (f) So sánh kết quả tại Trạm Khí tượng Nam Định.

\subsection{Kết quả kiểm định số liệu quan trắc tại Trung tâm quản lý}

Đánh giá số liệu được quan trắc tại Trung tâm quản lý cho một số nhận định như sau: (1) Số liệu được lưu dữ một cách khoa học, đường truyền ồn định; (2) Số liệu được đưa lên Web giám sát hoạt động: kttvtudong.net giao diện thân thiện, dễ giám sát số liệu, kịp thời có những thông tin cảnh báo khoa học, khai thác số liệu thuận tiện, phục vụ tốt công tác Dự 
báo và lưu dữ đánh giá chất lượng tài liệu; (3) Số liệu được giám sát trực quan trên nền web: http://kttvtudong.net//kttv. Một số kết quả hiện thị trên trang web được thể hiện trên hình 16 đến hình 18 và bảng 4,5 .

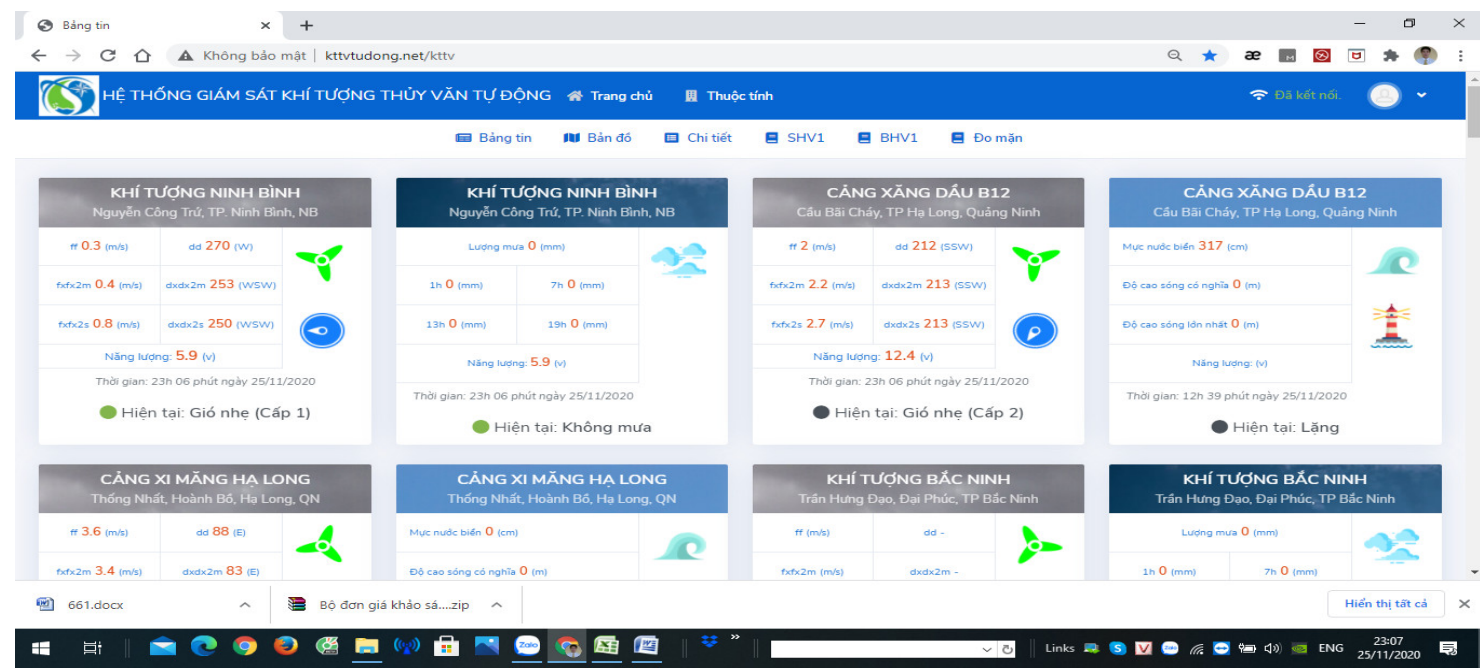

Hình 16. Giao diện Web giám sát.

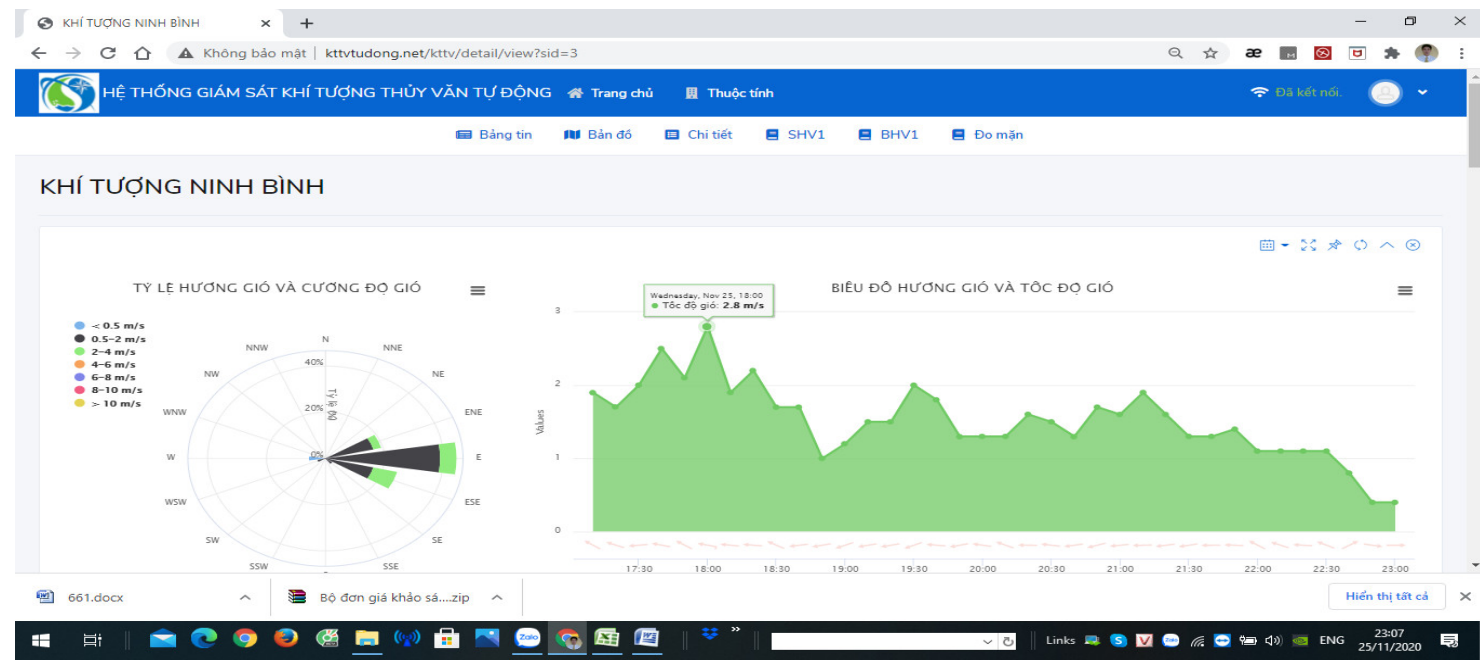

Hình 17. Hiển thị hoa gió, tốc độ, hướng gió.

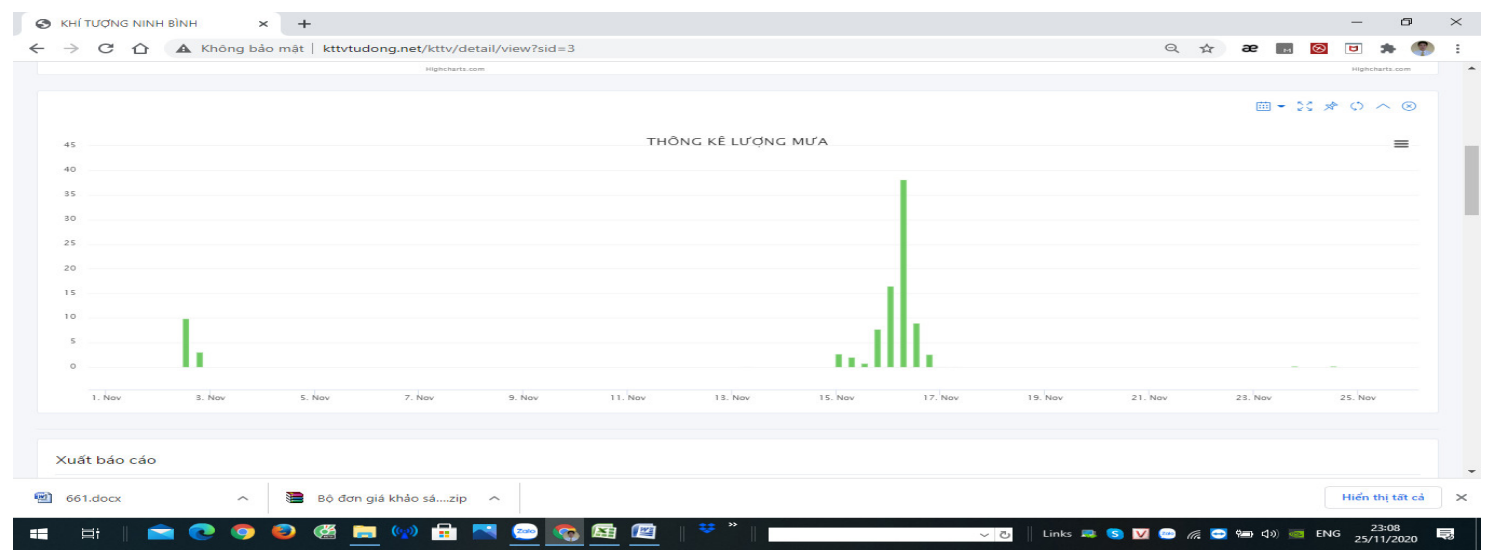

Hình 18. Biểu đồ mưa. 
Bảng 4. Bảng số liệu theo QĐ 357 theo dõi và khai thác.

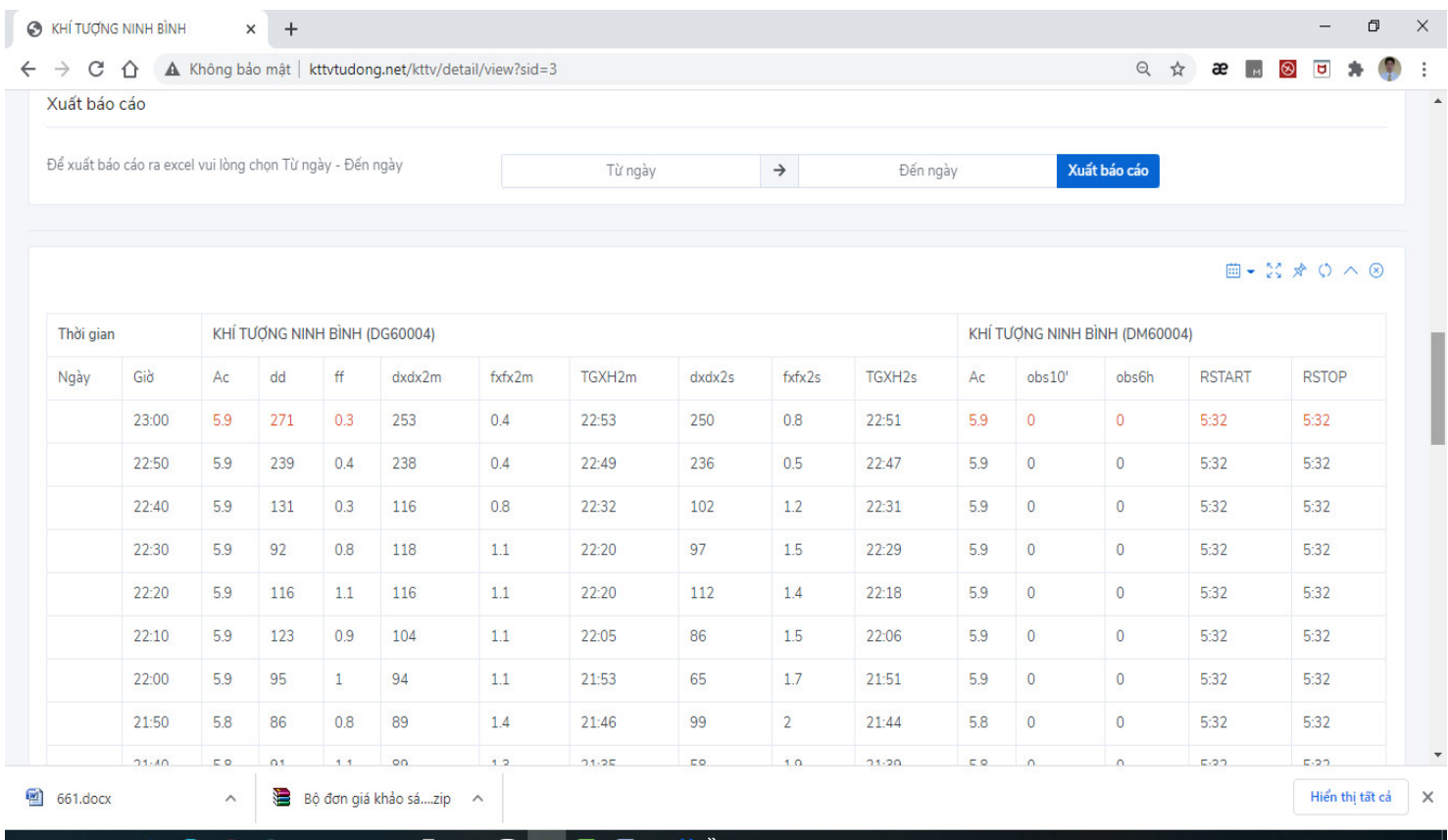

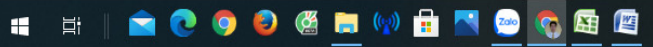

Bảng 5. Bảng số liệu khai thác từ kết quả trạm.

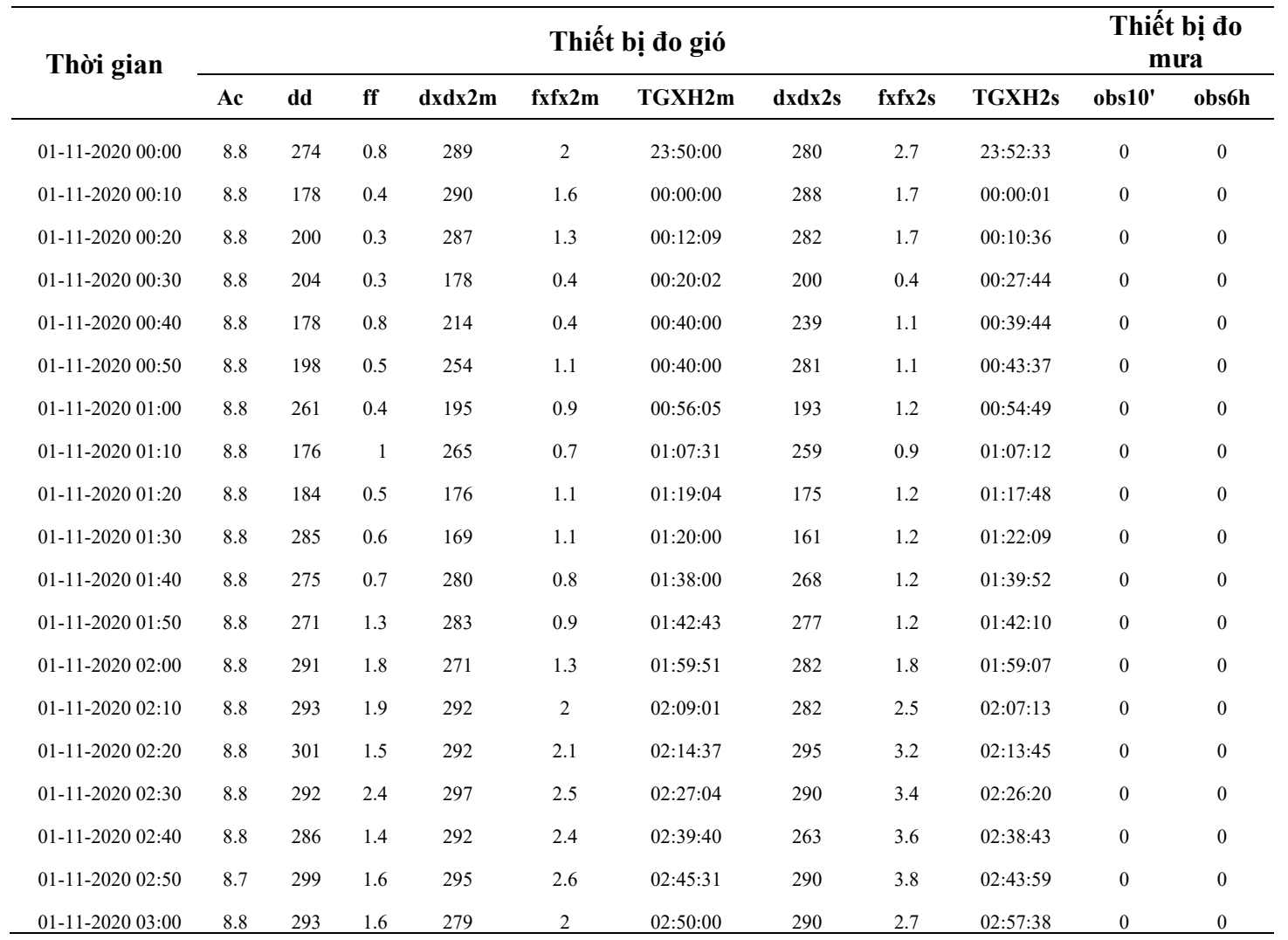




\section{Kết luận}

- Nghiên cứu cải tiến hệ thống truyền tin và tự động hóa cho các thiết bị đo mưa thủ công, gió bán tự động, gió tự động truyền tin bằng SMS trên khu vực đồng bằng Bắc Bộ phù hợp với sự phát triển và nhu cầu phát triển ngành.

- Việc Nghiên cứu cải tiến hệ thống truyền tin và tự động hóa cho các thiết bị đo mưa, gió thủ công trên khu vực đồng bằng Bắc Bộ được thực hiện theo đúng các quy định Thông tư hướng dẫn của Bộ Tài nguyên và Môi trường đã ban hành.

- Trong quá trình thực hiện đã tuân thủ các bước trong quy trình Nghiên cứu cải tiến hệ thống truyền tin và tự động hóa cho các thiết bị đo mưa, gió thủ công.

Đóng góp của tác giả: Xây dựng ý tưởng nghiên cứu: N.H.T.; Lựa chọn phương pháp nghiên cứu: N.H.T., D.V.S.; Xử lý số liệu: N.H.T.; Phân tích mẫu: N.H.H., N,H,T., D.V.S.; Lấy mẫu: N.H.H., N.H.T., D.V.S.; Viết bản thảo bài báo: N.H.T.; Chỉnh sửa bài báo: N.H.T.

Lời cảm ơn: Nghiên cứu này được thực hiện dưới sự tài trợ của đề tài nghiên cứu khoa học cấp cơ sở "Nghiên cứu cải tiến hệ thống truyền tin và tự động hóa cho các thiết bị đo mưa thủ công, gió bán tự động, gió tự động truyền tin bằng SMS trên khu vực đồng bằng Bắc Bộ", Mã số: CS.2020.05.11.

Lời cam đoan: Tập thể tác giả cam đoan bài báo này là công trình nghiên cứu của tập thể tác giả, chưa được công bố ở đâu, không được sao chép từ những nghiên cứu trước đây; không có sự tranh chấp lợi ích trong nhóm tác giả.

\section{Tài liệu tham khảo}

1. Quyết định Số: 929/QĐ-TTg ngày 22 tháng 06 năm 2010 của Thủ tướng Chính phủ. Đến năm 2020, mạng lưới quan trắc khí tượng thủy văn có mật độ trạm tương đương với các nước phát triển và tự động hóa trên $90 \%$ số trạm quan trắc, 2010.

2. Hân, N.V. và cộng sự. Nghiên cứu hệ thống đo mưa tự động Với việc kết hợp cảm biến đo theo nguyên lý chao lật tích hợp với mạch vi điện tử hình thành mạng lưới quan trắc mưa tự động, 2010.

3. Quyết định số 357/QĐ-KTTVQG ngày 21 tháng 7 năm 2014 về việc "Ban hành quy định dạng file số liệu, tần suất đo và truyền số liệu trạm khí tượng thủy văn tự động, 2014.

4. Thắng, T.V. và cộng sự. Triển khai đề tài NCKH cấp Bộ "Nghiên cứu xây dựng hệ thống tự động quản lý, truyền và nhận số liệu KTTV và hải văn ứng dụng mạng riêng ảo VPN tại Trung tâm KTTV quốc gia”, 2010.

5. Dũng, N.K. và cộng sự. Thực hiện nghiên cứu xây dựng giải pháp quản lý mạng lưới các trạm KTTV và hải văn tự động để tăng cường công tác quản lý và giám sát từ xa, 2015.

6. Hân, N.V. và cộng sự. Nghiên cứu Modem truyền tin hệ thống đo gió từ loại máy đo gió Young 26700 và 26800 của Mỹ được sử dụng cho các trạm Khí tượng, 2013.

7. WMO. https://public.wmo.int/en. 


\title{
Research to improve the information transmission and automation system for manual rain and wind measuring equipment in the Northern Delta
}

\author{
Nguyen Huu Tai ${ }^{*}$, Dao Van $\mathrm{San}^{2}$, Nguyen Hong Hanh ${ }^{3}$ \\ ${ }^{1}$ Center for Hydrometeorological Observation; taikttv@gmail.com \\ ${ }^{2}$ Hydrometeorology Station of the Northern Delta region; sandaovankttv@gmail.com \\ ${ }^{3}$ Hydrometeorology Station of the Northern Delta region; hanh1983hn@yahoo.com
}

\begin{abstract}
Over the past time, the unusual and extreme weather events in Vietnam have become more and more complicated. To tackle this situation, the requirement for monitoring data requires accuracy and timeliness. According to the Development Strategy of Meteorology and Hydrology sector up to 2020, our state's view of the industry is: synchronous development towards modernization; Using investment in science, technology and human resource training as the main solution for development on the basis of inheriting and maximizing existing resources; to fully exploit domestic scientific and technological achievements, at the same time to selectively apply advanced scientific and technological achievements in the world. Implementing the above strategy, the monitoring network and measurement monitoring technology have been gradually modernized. The station has been boldly carrying out a number of studies to improve the service quality of the network of meteorological, hydrological and environmental monitoring stations. Among those studies is the Research on improving communication system and automation for manual wind and rain measuring equipment.
\end{abstract}

Keywords: Manual equipment integration; Semi-automatic rain measuring equipment; Wind measurement. 